\title{
Agricultura e dinâmicas do desenvolvimento rural no contexto da globalização
}

Cláudio Machado Maia ${ }^{1}$ Mario Riedl²

\begin{abstract}
Resumo
Este artigo é de caráter exploratório e visa contribuir para a compreensão do processo de desenvolvimento e da inserção da agricultura num contexto de globalização vis-à-vis, elementos que têm conformado a evolução e a reestruturação da agricultura. Para tanto, são apresentadas reflexões sobre globalização, sua caracterização, gênese, impactos e mudanças, e a questão do Estado-Nação, assim como interpretações de dinâmicas de desenvolvimento rural. É construído com base em diversas fontes bibliográficas, tendo como conclusão uma síntese sobre a abordagem territorial do desenvolvimento como alternativa analítica que considera a composição e a complexidade do mundo rural, uma abordagem que serve como modelo de análise. Numa reflexão de abordagem comparativa, apresentase uma breve caracterização do processo de desenvolvimento rural no âmbito dos países do sul da Europa e latino-americanos. Resumidamente, são apresentadas considerações em torno de elementos que podem favorecer o processo de desenvolvimento rural, tais como o papel dos atores do processo de desenvolvimento e das práticas participativas da sociedade; das ações dos indivíduos e organismos sociais, das organizações e das instituições. Enfim, uma reflexão sobre o desenvolvimento que remete à compreensão das problemáticas e das políticas de promoção do desenvolvimento.
\end{abstract}

Palavras-chave: Globalização. Desenvolvimento Rural. Agricultura. Mercado. Participação Social.

\begin{abstract}
Therefore, reflections on globalization, its characterization and genesis, impacts, changes and the question of the nation-state, as well as, interpretations of rural development dynamics are presented. It is based on several bibliographical sources, having as conclusion a synthesis on the territorial approach to development as an analytical alternative that considers the composition and complexity of the rural world, an approach that serves as a model of analysis. In a reflection of a

\footnotetext{
${ }^{1}$ Doutor em Desenvolvimento Rural. Professor do Programa de Pós-Graduação em Políticas Sociais e Dinâmicas Regionais da Universidade Comunitária Regional de Chapecó (Unochapecó). claudiomaia.dr@hotmail.com

2 Doutor em Sociologia. Professor do Programa de Pós-Graduação em Desenvolvimento Regional das Faculdades Integradas de Taquara (Faccat/RS). miriedl@terra.com.br
} 
comparative approach, a brief characterization of the rural development process is presented in the countries of Southern Europe and Latin America. Briefly, considerations are presented about elements that can favor the process of rural development, such as the role of actors in the development process and participatory practices of society, the actions of individuals and social organisms, organizations and institutions. Finally, a reflection on development that refers to the understanding of issues and policies to promote development.

Keywords: Globalization. Rural Development. Agriculture. Market. Social Participation.

\section{Globalização}

O verdadeiro nome da globalização é mundialização do capital, um processo de desenvolvimento do capitalismo mundial que possui características particulares e que não pode ser confundido com a expansão do mercado mundial ou de outras fases de desenvolvimento do capitalismo moderno. Falar de mundialização do capital é referir-se a um regime de acumulação que se caracteriza pela predominância hegemônica do capital financeiro na dinâmica da acumulação de riqueza capitalista (MACHADO, 2003).

Em primeiro lugar, pelas suas próprias características de privilegiar os agentes financeiros em detrimento do crescimento econômico e da produção, sob a promessa de uma suposta modernização, tendo, dessa forma, o impacto direto no mundo do trabalho e na produção, contribuindo para o aumento do desemprego estrutural e das formas de precarização do estatuto salarial da força de trabalho. Em segundo lugar, por acirrar uma lógica intrínseca à própria modernização capitalista, o processo de financeirização tende a ser seletivo, excludente e desigual, pois passa a selecionar países, regiões e setores da economia cuja rentabilidade líquida e segura Ihe interessam. Em terceiro lugar, a crescente mundialização do capital explicita sua face mais áspera no seu descontrole como processo sociometabólico, atingindo a modernidade capitalista ${ }^{3}$ (MACHADO, 2003).

Entretanto, neste ambiente de predominante descontrole, os países e regiões que têm obtido melhores resultados na economia nos últimos anos foram aqueles que conseguiram com maior eficiência dirigir e controlar políticas públicas externas que beneficiassem seus interesses, priorizando seus atores locais no processo de desenvolvimento. Conforme Machado (2003, p. 15), "[...] a decisiva capacidade de controles de alguns atores em tal cenário é, portanto, elemento chave para se entender o desenvolvimento desigual, fragmentado e contraditório que se observa hoje nos diferentes locais".

O desafio desta reflexão é dar andamento a uma série de estudos e deba-

\footnotetext{
${ }^{3}$ Sobre esse conceito, a globalização pode ser vista como resultado histórico da derrota política dos trabalhadores em seus polos mais organizados e da ofensiva do capital nos vários campos da vida social. Tal incontrolabilidade do capital financeiro pode ser vista também como a perda de controle dos agentes sociais.
} 
tes que têm sido desenvolvidos, considerando os desafios para o desenvolvimento territorial que tem emergido das dinâmicas geradas pelos processos de integração regional conjugados com a consolidação da globalização e de fenômenos associados às complexas relações entre o global e o local, numa perspectiva comparada, sendo que neste estudo consideram-se reflexões sobre o MERCOSUL e União Europeia, especificamente, da realidade latino-americana e da Europa do Sul.

Nuestras investigaciones y reflexiones se inscriben en la problemática general en torno a la globalización y el desarrollo territorial en el marco de los procesos de integración. Las mismas abarcan espacios regionales que experimentan dinámicas de cambio de natureza diferente, lo que permite un análisis comparado que enriquece nuestros estudios y perspectivas sobre dichos fenómenos. Por un lado, en la zona central del MERCOSUL se abre una problemática de integración en un espacio regional transnacional. Este vasto territorio conformado por el Uruguay, las provincias vecinas de Argentina y los Estados sureños de Brasil, tiende a convertirse en un foco económico y político de envergadura. Por otra parte, el conjunto de regiones del sur de la Unión Europea, a pesar de no conformar un espacio regional único, resulta relevante desde el punto de vista de la dialéctica espacio regional espacio comunitario. Además, ambas regiones si bien tienen niveles de urbanización relativamente altos y una red de ciudades intermedias, en términos territoriales se caracterizan por la presencia de una agricultura empresarial de corte productivista fuertemente integrada en los complejos agro alimenticios. A su vez, en ambas áreas se mantiene en forma significativa una agricultura familiar de la cual depende en parte importante la vitalidad y la sustentabilidad de los territorios rurales y su integración en las dinámicas globales (RIELLA4, 2006, p. 7-8).

Considera-se que os estudos sobre globalização apresentam vastas perspectivas de interpretações e o caráter multifacetário das transformações observadas, relacionadas com as diferentes associações entre mudanças globais e consequências locais ${ }^{5}$. Cabe aqui esclarecer um pouco mais sobre este termo e sua relação com a perspectiva analítica aqui apresentada.

Este processo de mudança tem sido modificado ao longo do tempo e adquirido diferentes significados. Conforme afirma Sztompka (1995), as sociedades antigas vivenciaram um completo mosaico de unidades sociais, que viviam frequentemente isoladas e eram extremamente diversificadas. Havia múltiplas entidades políticas separadas, que iam desde as hordas, as tribos, os reinos, os impérios, até a forma relativamente recente de dominação, que é a dos EstadosNação. As economias eram independentes, fechadas, autárquicas, e variadas culturas indígenas conservavam sua identidade única. A sociedade atual apresenta um quadro completamente diferente (SZTOMPKA, 1995). Neste ínterim, houve

\footnotetext{
${ }^{4}$ Coordenador Geral da Rede de Desenvolvimento Territorial e Integração Regional (ReDeTIR) no âmbito do Programa ALFA II-0541-FA (Europe Aid Co-operation Office). Professor e investigador do Departamento de Sociologia de la Faculdad de Ciencias Sociales de la Universidad de la República, Uruguay.

${ }^{5}$ Conforme Machado (2003, p. 74), "a palavra globalização converte-se num termo adequado para designar de forma mais geral a uma força que atua em diferentes dimensões, superior a vontade dos atores individuais ou coletivos locais".
} 
enorme processo de mudança, cujos pontos de intersecção, contato e ruptura local estão descritos ao longo da história da humanidade.

Por outro lado, Moreira ${ }^{6}$ (2006) descreve que

Globalização é um conceito recente e polissêmico que, mau grado o vastíssimo e sempre crescente acervo bibliográfico que lhe é dedicado, está longe de se poder considerar consolidado e de aceitação universal. Neste texto, globalização é entendida como o resultado de um processo dialético e desigual de compressão do espaço e do tempo que envolve um sistema de forças muito diversificadas. Forças econômicas, sociais, políticas, ideológicas e até religiosas que, desde as últimas três décadas do século XX, vêm modelando e remodelando a divisão internacional de trabalho, favorecendo a acumulação de capital e promovendo a homogeneização dos comportamentos e dos consumos humanos ou a elas se opõem (MOREIRA, 2006, p. 17).

Nesta perspectiva, no centro da globalização, está o capital financeiro internacional ${ }^{7}$, que desenvolve estratégias para adaptar os padrões de acumulação a condições geoeconômicas e geopolíticas em mudança acelerada num ambiente econômico de crescimento do poder de compra de parte significativa dos países e populações mais diretamente envolvidos pelos fenômenos acima descritos. Conforme Moreira (2006), embora a globalização tenha ambição planetária, tem sobretudo que ver com os países da tríade EUA, Europa Ocidental e Japão, deixando muitas áreas e populações mais pobres como meros sujeitos passivos, ou completamente à parte das manifestações econômicas do fenômeno.

Sobre esta problemática da globalização, apresenta-se aqui uma interpretação dos processos de ampliação dos mercados mundiais que deram forma à globalização atual e estabeleceram suas regras. Entretanto, é possível substituir o acerto político que criou este estilo de globalização por outro (ou políticas) que oriente o aumento da integração entre as sociedades do mundo em torno dos objetivos de equidade social para solução de problemas nacionais que hoje aparecem como sem solução (MOREIRA, 2006).

Inspirado em Riella (2006), esta reflexão:

[...] busca ser un aporte a la reflexión sobre dichas políticas para alentar a que sean diseñadas con un abordaje interdisciplinario que considere el desarrollo territorial como una construcción social fortaleciendo las instituciones, las acciones colectivas, la gestión participativa e el fomento cuidadano sobre los territorios menos favorecidos por las dinámicas económicas globales (RIELLA, 2006, p. 13).

Conforme apresentado por Moreira (2006), para se entender a dimensão econômica da globalização, tal como a conhecemos na atualidade, deve-se levar em consideração os fenômenos de agency, que passaram a existir pela conjugação de vários fatores. Agency, entendida como o resultado da ação política em

\footnotetext{
${ }^{6}$ Pesquisador da ReDeTIR. Professor no Departamento de Economia Agrária e Sociologia Rural do Instituto Superior de Agronomia, Universidade Técnica de Lisboa, Portugal.

7 Entendido em sentido lato como o conjunto das empresas transnacionais e as instituições financeiras com dimensão e âmbito de atuação transnacional.
} 
grande parte determinada por uma agenda ideológica que, também ela, resulta de fenômenos de agency ${ }^{8}$.

Na gênese desse processo, de um lado, assumem papel determinante certos fenômenos no âmbito do político e do ideológico, os quais estão na base da hegemonia ideológica neoliberal, e, de outro lado, estão considerações geopolíticas ligadas aos interesses da potência hegemônica9 .

Conforme Moreira (2006), a agenda ideológica neoliberal resulta de fenômenos de agency decorrentes da ação de influentes grupos de reflexão que, ao longo dos anos, foram capazes de desenvolver uma ação persistente de estudo teórico, pesquisa empírica e propaganda, revelando resultados eficientes. Tais grupos de reflexão envolvem acadêmicos de reputação, capitalistas com vocação filantrópica ideologicamente orientada, que os financiam, políticos influentes, que vão desde jovens promissores até os que ocupam cargos de dirigentes e que também canalizam verbas estatais para esses fins, ou os que se fazem ouvir pela opinião pública, ou mesmo proprietários ou diretores de órgãos de comunicação e influentes jornalistas. Em resumo, individualidades que, além de serem capazes de financiar esses grupos de reflexão (think tanks), dada sua influência na opinião pública, são transformados em fazedores de opinião pública (opinion makers), com presença constante nos órgãos de comunicação social, muitas vezes a eles ligados por formas contratuais ou outras.

Em termos geopolíticos, apresenta-se a posição convergente dos críticos de esquerda, que afirmam ser a globalização uma nova roupagem do imperialismo americano, ou a posição de observadores do establishment americano, como o antigo secretário de estado americano Henry Kissinger, que afirmou tratar-se de uma nova palavra para caracterizar o papel dominante da América no mundo, ou mesmo Lawrence Summers, responsável do Tesouro, na administração Clinton (e integrante do governo de Barack Obama como conselheiro econômico de janeiro de 2009 a novembro de 2010), que afirma "[...] a nossa ideologia, o capitalismo, está em ascensão em todo o lado", defendendo que é do interesse, para a segurança da América, assegurar-se de que todos os países seguem o globalizador Consenso de Washington ${ }^{10}$ (LAXER, 2003, p. 138-139 apud MOREIRA, 2006, p. 19).

No entanto, esta visão é bem restrita, pois, mesmo que seja importante o impulso dado à globalização pelos EUA, o fenômeno não é eminentemente

\footnotetext{
${ }^{8}$ Fenómenos de agency que configuram exemplos de organized agency ou o resultado de atos conscientes e deliberados em contraponto à spontaneous agency (MOREIRA, 2006).

${ }^{9}$ Conforme Moreira (2006), mesmo aceitando-se a posição de Wallerstein (2001) sobre a forte diminuição do poder que vem ocorrendo, desde os anos 50 do século passado, defende-se que os EUA são a potência hegemônica. A supremacia militar e o peso determinante dos EUA nas organizações internacionais como o Banco Mundial, o Fundo Monetário Internacional ou até mesmo a OCDE reforçam esta tese. Mesmo que necessitando do suporte das outras economias desenvolvidas, os EUA detêm a liderança no centro do G7, o fórum onde acontece grande parte da política econômica internacional e o sentido da globalização acaba por ser determinado.

${ }^{10}$ Consenso de Washington que impõe aos países dependentes a receita da liberalização, da privatização e da desregulação e, como corolário, a exigência de equilíbrio orçamental, da chamada verdade dos preços e da recusa de subsídios estatais para os mais desfavorecidos, embora não se oponha à concessão de apoios estatais para atrair o capital global.
} 
americano. Assim como não se aceita a ideia de que não importa a nacionalidade da origem das transnacionais só pelo argumento de que é o capital global o dinamizador da globalização. Entretanto, numa posição intermediária, defende-se que a globalização decorre da relação dialética do capital com os diferentes estados-nação, onde aos aspectos estruturais inerentes a essas relações se juntam as contingências consequentes de contextos diferenciados e dos fenômenos de agency que acabaram por se revelar determinantes para o iniciar da globalização.

Outra perspectiva de análise para abordar a globalização é desenvolvida por Rodrik (2002), naquilo que define como trilema político da economia global, descrevendo que o sistema Estado-Nação, políticas democráticas e integração econômica total não são compatíveis. Segundo o autor, a globalização é uma alternativa de melhoria do padrão de vida, ao mesmo tempo em que a democracia garante que as decisões políticas possam ser tomadas pelos que são diretamente afetados por elas (ou pelos seus representantes), e não se abdicando da autodeterminação que se exprime através dos Estados-Nação. E que não é possível assegurar simultaneamente essas três condições, uma vez que seguir a direção de mercados globais sem governança global é insustentável. Quanto muito, para diferentes situações, assegura-se que ocorram no máximo duas dessas condições (ou polos) do trilema.

Figura 1 - The political trilemma of the world economy

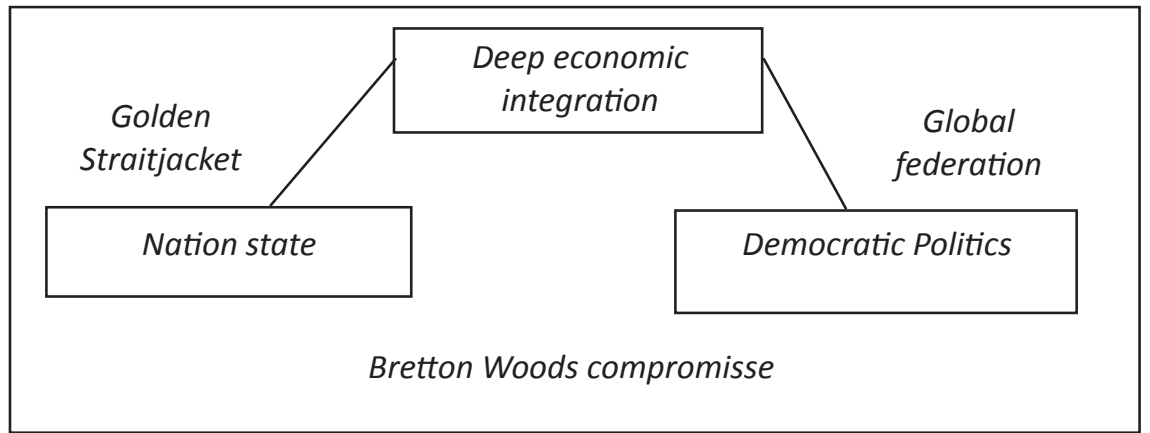

Fonte: Rodrik (2002, p. 25).

Satisfazer os três polos ao mesmo tempo levaria a uma situação extrema que mais pareceria de ficção científica ${ }^{11}$, situação que, por mais que sejam poderosas as forças globalizadoras, não parece viável num horizonte temporal de médio prazo ${ }^{12}$, mostrando-se claramente incompatível com os processos democráticos correntes e com a manutenção de uma ordem mundial baseada em Estados-Nação soberanos e independentes.

Importa esclarecer que, se a hegemonia ideológica neoliberal pode legi-

\footnotetext{
$\overline{11}$ Numa exemplificação apresentada por Rodrik (1998), vê-se: numa economia mundial completamente integrada economicamente, teríamos uma situação em que o preço da mão de obra seria aferida pelos salários de Shenzen (China), o preço do dinheiro seria fixado em Wall Street e a fiscalização determinada pelos padrões das ilhas Caimão.

${ }^{12}$ Médio prazo, no sentido de Keynes, para quem, no longo prazo, estaremos todos mortos.
} 
timamente ser considerada como condição necessária para a globalização que conhecemos, não pode ser tida como condição suficiente, uma vez que outras condições são necessárias e levadas em consideração, tais como condições materiais, como o desenvolvimento das tecnologias de transporte, da logística e, principalmente, a revolução nas tecnologias de informação (CASTELLS, 1996 apud MOREIRA, 2006; CASTELLS, 2003 ${ }^{13}$ ). Ou seja, o entendimento é de que, na gênese do processo de globalização interessante ao capital financeiro internacional, estão as decisões políticas. Decisões que puseram em marcha um processo que inaugura uma outra fase do capitalismo mundial ${ }^{14}$. Aspectos que apresentam mudanças tanto qualitativas quanto quantitativas no panorama do capitalismo mundial, justificando a variada produção teórica sobre um novo conceito para delas dar conta, a globalização (MOREIRA, 2006).

Importa nessa gênese um processo que, ao longo dos anos, a indispensabilidade da intervenção do Estado na economia, ao estilo keynesiano, não questionado desde a grande depressão, foi substituído pela retórica da recusa dessa intervenção ${ }^{15}$.

\section{Da globalização ao território: território como categoria de análise}

À oposição local - global, as noções de território e de globalização são antagônicas e, por isso mesmo, complementares e inseparáveis. A globalização caracteriza um movimento planetário que alcança todas as dimensões da vida, não somente a econômica, mas a vida social e cultural. Em suas expressões mais temíveis, é um movimento totalizador que ameniza todas as especificidades locais e culturais (LINCK ${ }^{16}, 2006$, p. 107). E é a partir desta visão, das pressões que envolve a globalização, que se apresenta um questionamento em torno da apropriação dos territórios. Conforme Linck (2006),

El territorio se desdibuja en contraste de este panorama sombrio. Se nos pinta con todos los atributos emblemáticos de la resistencia y de la nostalgia. El territorio se vuelve símbolo y lema, es una promesa, una respuesta y un recuerdo: el territorio es lo que la globalización no es, es todo aquello que la globalización amenaza y destruye: por esas razones, el territorio no puede ser otra cosa que el producto antitético de la globalización (LINCK, 2006, p. 107).

\footnotetext{
${ }^{13}$ As condições materiais acabam por determinar a rapidez e o alcance da globalização, mas só mostram efeitos práticos a partir do momento em que a situação amadurecer até um ponto em que, no nível da ação política, os decisores governamentais, sob pressão do capital internacional, conseguirem fazer passar as mudanças que criam as condições de exequibilidade do processo globalizador.

${ }^{14}$ Fase caracterizada, entre outras, pela mudança dos modelos de organização das empresas (crise do modelo fordista e emergência do pós-fordismo); pela liberalização do comércio internacional; pelo crescimento do investimento direto no estrangeiro; pelo surgimento de um verdadeiro mercado financeiro globalizado, caracterizado pela liberdade dos movimentos de capitais, bem diferente dos mercados financeiros do passado.

${ }^{15}$ Conforme Moreira (2006, p. 24), diz-se retórica porque o capital não deixa de exigir a intervenção estatal sempre que dela necessita, como foi amplamente documentado na resposta à crise financeira de 2007/2008.

${ }^{16}$ ReDeTIR e INRA - Systemes de Décision pour le Dévelopment. 20250 CORTE, Francia.
} 
Baseado na descrição apresentada por Link (2006), tudo isso é demasiado simples: o território é algo mais do que uma simples antítese. Por outro lado, a globalização exerce um efeito perverso. Mas, além de suas expressões concretas, difunde largamente, ao longo do planeta, novas expressões do mundo e das dinâmicas sociais que prosperam da ilusão neoliberal.

Certamente, hoje em dia, predomina o sentimento de que, em um mundo imperfeito, dificilmente se pode esperar que a concorrência e o mercado vão gerar virtudes, prosperidade e justiça social. O mercado, agora, desperta menos expectativas que dúvidas e fatalismo: mas, goste ou não, o mercado existe. A queda das grandes instituições e a debilidade dos Estados nacionais confirmam esta evidência: o mercado convertido no principal, senão o único, dispositivo de regulação econômica. Essa evidência e essa renúncia apresentam um consenso perverso: se o mercado domina a economia, é de vital importância dissociar a construção das eleições coletivas - ou seja, o político - da esfera da economia. E, reciprocamente, unem-se em uma mesma postura dois pontos de vista radicalmente opostos. De um lado, considera-se necessário dissociar ambas as esferas para preservar o mercado e a economia da ingerência dos políticos (o princípio de eficiência segundo o ponto de vista liberal). Por outro lado, a dissociação é necessária para proteger os espaços políticos da influência do mercado (ponto de vista radical). Quer se trate de fatalismo, de convicção, de renúncia ou de resistência, assume-se uma separação tangente entre o econômico (o que remete e/ou se abandona às forças do mercado) e o político (no âmbito da concertação e da expressão cidadã). De um lado está o que se supõe procedente do cálculo e do interesse privado, e, do outro, o que remete aos valores superiores de solidariedade e de cidadania ${ }^{17}$.

Esta dimensão, em parte, explica a reinvenção dos territórios.

Si el territorio es lo que la globalización no es y si la globalización es el imperio del mercado, entonces el territorio tiene que excluir los principios de cálculo y de interés individual que sustentan el racional choice de los economistas liberales (LINCK, 2006, p. 109).

Se não alcança uma posição de destaque, o território se conserva como o cenário comum dos valores sociais que formam consenso, marcam identidade e solidariedade. Percebe-se como um espaço de dimensões humanas, com características comunitárias, onde predominam a confiança e o interconhecimento, não havendo contradições relevantes para o acesso às riquezas e ao controle dos processos produtivos.

O território tem as noções de participação, de concertação, de adesão, de

\footnotetext{
${ }^{17}$ Naturalmente, esta representação se sustenta em uma visão bastante aquém do que é a economia e que tendemos a repensar. Acima de tudo, legitima um despojamento de capacidades: o cidadão não tem porque - nem pode - opinar sobre a produção de riquezas, sobre o seu equilíbrio entre os diferentes componentes da sociedade, sobre os fluxos de investimentos (e da própria ideia de planejamento econômico), sobre as contradições entre capital e trabalho e justiça social... Nesse sentido, a globalização instrui a uma diluição da própria essência do debate político: a negação da globalização é política (LINCK, 2006).
} 
coesão social e sua confusão com as ambiguidades que a "boa governança" sugere... Tal representação do território é útil para dar ênfase às ambiguidades do termo e evidenciar algumas de suas "armadilhas". Território é um conceito que pode ser utilizado independente da globalização. Ao menos tem mobilizado a geografia humana, a antropologia, a arqueologia, a sociologia e a economia, entre outras áreas do conhecimento que foram vistas muito antes de se falar em globalização.

Conforme Link (2006), a construção desta interpretação movimenta algumas referências. Afirmar que território não deve ser confundido com a noção de espaço ou de área decorre de uma evidência: o território é um espaço com personalidade própria, que nenhuma lei geométrica permite entender ${ }^{18}$. Também é uma evidência afirmar que o território é uma construção social: o território tem história, uma identidade, e é precisamente isso que o enfoque territorial permite entender. Não restaram talvez evidentes todas as implicações dessa asserção. Em primeiro lugar, o território é um espaço apropriado: reconhecer as formas dessa apropriação, entender as modalidades de sua legitimação e identificar os seus beneficiários lança algumas dificuldades. Lógico, mas nem por isso evidente que tanto a apropriação como a construção do território são coletivas: produzir um território não é obra de apenas um indivíduo isolado, mas sim de um grupo. Assume que o território é a vez do cenário e do objetivo da ação coletiva. Focaliza simultaneamente relações de competência e de cooperação, sendo objeto de conflitos que são revolvidos e superados na construção da solidariedade e/ou da hierarquia. É neste ponto que o território pode tomar seu sentido de patrimônio coletivo, que se mobiliza em um processo de produção da sociedade. É precisamente em torno do manejo e das modalidades de apropriação deste patrimônio que têm sentido as interações e as contradições entre territórios e globalização.

O território se projeta na história como um espaço onde há construções institucionais: há uma exigência de ruptura com o universo unidimensional do intercâmbio mercantil, do cálculo e do interesse individual. É um recurso produtivo, manejado e valorado coletivamente, portanto há exigência de uma gestão social que remete para critérios e estratégias que nenhuma regra natural nem princípio superior permite entender. Esta definição leva ao debate da construção das decisões coletivas e do manejo de recursos compartilhados. O território, ao mesmo tempo em que é objeto de conflitos e de rivalidades entre usuário, conforma a substância de um projeto coletivo. Falar de território, e mais ainda em relação à globalização, implica quebrar um consenso: temos que ultrapassar a dissociação

\footnotetext{
${ }_{18}$ Intuitivamente, parte-se do raciocínio de que o território é fundamentalmente definido e delimitado por e a partir de relações de poder. A questão que se coloca é quem domina ou influencia e/ou como domina ou influencia determinado espaço. $\mathrm{O}$ 'poder' corresponde à habilidade humana de não apenas agir, mas de agir em uníssomo, em comum acordo. O poder jamais é propriedade de um indivíduo; pertence ele a um grupo e existe apenas enquanto o grupo se mantiver unido. Quando dizemos que alguém está 'no poder', estamos na realidade nos referindo ao fato de encontrar-se esta pessoa investida de poder, por um certo número de pessoas, para atuar em seu nome. No momento em que o grupo, de onde se originara o poder (potestas in populo, sem um povo ou um grupo não há poder) desaparece, 'o seu poder' também desaparece (ARENDT, 1985, apud SOUZA, 1995).
} 
entre economia e política, enfatizando o fato de que a construção e avaliação dos territórios está na interseção de ambos os campos (LINK, 2006).

Para Abramovay (2007), a noção de território favorece o avanço dos estudos rurais pelo menos em quatro dimensões:

a. Abandona-se um horizonte estritamente setorial - sob o ângulo operacional - ruralidade torna-se uma categoria territorial cujo atributo decisivo está na organização de seus ecossistemas, na densidade demográfica relativamente baixa, na sociabilidade de interconhecimento e na sua dependência com relação às cidades; sob uma perspectiva teórica, territórios não se definem por limites físicos, e sim pela maneira como se produz, em seu interior, a interação social. Os estudos rurais puderam se beneficiar das contribuições neomarshallianas, sobretudo, de economistas italianos (por exemplo, Becattini) e franceses (RequierDesjardins e Bernard Pecquer) que abordaram a importância da cooperação e da partilha de conhecimentos e de experiências entre atores na formação do ambiente que permitiu o desenvolvimento de algumas regiões italianas ${ }^{19}$.

b. A segunda virtude da noção de território é impedir a confusão entre crescimento econômico e processo de desenvolvimento. Por exemplo, a pobreza passa a ser encarada como um fenômeno multidimensional. A abordagem territorial, além disso, exige a análise de instituições em torno das quais se organiza a interação social localizada, não se tratando apenas de examinar como se formam e como podem ser reduzidos os custos de transação, e sim de abordá-los sob um ângulo histórico e a partir da influência que sobre eles exercem as forças sociais que os constituem (NORTH, 1991, p. 97-98; NORTH, 1994, p. 362-363).

c. Sendo assim, o estudo empírico dos atores ${ }^{20}$ e de suas organizações é crucial para a compreensão de situações localizadas. Já que um dos principais problemas das organizações territoriais de desenvolvimento em meio rural é a sua dificuldade em ampliar sua composição social além da presença dos representantes da agricultura (perspectiva setorial), processos de cooperação entre municípios podem ser um meio de atenuar tal propensão a adquirir, na prática, um perfil de caráter setorial. A abordagem territorial do desenvolvimento estimula o estudo de mecanismos de governança pública em torno à composição e à atuação dos conselhos de desenvolvimento em torno da pergunta: são capazes de oferecer oportunidades de inovação organizacional que

${ }_{19}$ Mesmo que a experiência italiana, evidentemente, não possa ser transportada para outras regiões, seu estudo contribui para realçar o papel dos atores e das organizações no processo de desenvolvimento - daí, conforme Abramovay (2007) coloca-se ênfase em dimensões subjetivas da interação, o que resultou na ideia de regiões de conhecimento, cidades de aprendizagem e territórios inteligentes.

20 É claro que esses atores provêm de vários setores econômicos e possuem origens políticas e culturais diversificadas. 
estimulem o empreendedorismo privado, o público e o associativo em suas regiões respectivas?

d. O território dá ênfase à maneira como uma sociedade utiliza os recursos de que dispõe em sua organização produtiva, e, portanto, na relação entre sistemas sociais e ecológicos. Territórios são resultados da maneira como as sociedades se organizam para usar os sistemas naturais em que se apoia sua reprodução, o que abre um interessante campo de cooperação entre ciências sociais e naturais no conhecimento dessa relação - a questão multidisciplinar.

Conforme Maia (2016),

a introdução de uma nova representação do espaço, o espaço local (espaço-território) e a articulação entre as várias escalas espaciais (do local ao global), em alternativa à representação em uma única escala, a nacional, permitiu revelar fenômenos econômicos, sociais, políticos e culturais importantes que antes estavam escondidos, ou eram ignorados, ou tomados como vestígios do passado, entraves ao processo irreversível de nacionalização do espaço (MAIA, 2016, p. 290).

É precisamente quando esta nacionalização enfraquece perante a crescente importância da escala global, globalização em nível econômico e financeiro, que os fenômenos localizados se revelam e lhes é reconhecida importância teórica. Num paradigma territorialista, que define o espaço-território assente numa sociocultura comum, com um espaço apropriado, onde se formulam estratégias baseadas na solidariedade existente em nível local.

\section{Interpretando dinâmicas de desenvolvimento rural: o Brasil, o contexto latino-americano, a União Europeia - uma tentativa de comparação}

Pelo menos nas últimas três décadas, a temática desenvolvimento rural tem ocupado lugar de destaque na literatura acadêmica, em documentos e ações de instituições e organizações políticas em todo o mundo. Conforme Kageyama (2008), no Brasil, até recentemente, o debate girava em torno da economia agrícola, do agronegócio e de seus mercados. Entretanto, a produção acadêmica brasileira sobre o desenvolvimento rural vem crescendo bastante nos últimos anos e atestando tal importância, não somente para os estudiosos mas para toda a sociedade.

Por outro lado, Kageyama (2008) descreve que a abordagem territorial da ruralidade e do desenvolvimento rural foi também introduzida no principal órgão de políticas públicas para o meio rural no Brasil, o Ministério do Desenvolvimento Agrário (MDA) ${ }^{21}$, quando, para questão em torno do Conceito de Território e Abordagem Territorial, lê-se que ${ }^{21}$ Por meio da Secretaria de Desenvolvimento Territorial, que definiu 119 "territórios
rurais apoiados", cobrindo todos os estados brasileiros. 
O rural não se resume ao agrícola. Mais do que um setor econômico, o que define as áreas rurais enquanto tal são suas características espaciais: o menor grau de artificialização do ambiente quando comparado com áreas urbanas, a menor densidade populacional, o maior peso das fontes naturais (MDA, 2005, p. 8).

O desenvolvimento rural não se identificando com crescimento econômico, mas visto como um processo que envolve múltiplas dimensões, tais como a dimensão econômica, a dimensão sociocultural, a dimensão político-institucional e a dimensão ambiental (KAGEYAMA, 2008).

Conforme sintetizado por Stavenhagen (1985), nas três décadas do início dos anos cinquenta até fins dos anos setenta, predominou uma concepção linear evolucionista no pensar o desenvolvimento, onde o ponto de partida era o reconhecimento de que algumas regiões do mundo eram "atrasadas" econômica, social, cultural e até politicamente. Na época, o atraso, tal como era entendido, significava pobreza, fome, produto nacional baixo, baixa renda per capita e, em geral, baixos padrões de vida para grande parte da população. E o remédio para o atraso era o crescimento econômico. Diferentes estratégias eram elaboradas e colocadas em prática, visando ao crescimento econômico - enfatizavam a necessidade de recursos naturais, ou que o elemento-chave era o capital, a tecnologia ou a educação. Entretanto, concluiu-se que nem todos esses elementos juntos resolveriam o problema do atraso. Fez-se importante discussão em torno da distinção entre crescimento econômico enquanto tal (aumento de produto nacional e da renda per capita) e desenvolvimento numa perspectiva mais ampla e institucional. O desenvolvimento social e institucional tornou-se um componente importante.

Nos últimos anos, a crítica permanente da teoria do desenvolvimento conduziu a novas abordagens, passando-se a buscar estratégias alternativas de desenvolvimento por parte de alguns governos, de movimentos sociais de diversos tipos, de pequenos grupos de pesquisadores e planejadores, bem como de pessoas de diversas organizações internacionais. Tais abordagens contêm elementos que nem sempre aparecem em conjunto, embora se reconheça que seria mais benéfico se ocorressem ao longo do processo, alcançando um momento em que ocorressem conjuntamente.

Primeiramente, implica uma estratégia de abordagem voltada às necessidades básicas de um grande número de pessoas, mais do que ao crescimento econômico por si mesmo, considerando-se sempre como e para quem elas serão definidas. Procurando-se uma visão interna ou endógena, ou conforme Stavenhagen (1985), o desenvolvimento deve primeiro responder às necessidades do país, coletiva e socialmente, mais do que ao sistema internacional (numa visão externa e orientada para as exportações e importações), usando e aproveitando as tradições culturais existentes, e não as rejeitando a priori como obstáculos ao desenvolvimento, uma abordagem que se propõe a respeitar o meio ambiente, sendo válida do ponto de vista ecológico. Tal abordagem estaria baseada, sempre que possível, no uso dos recursos locais, quer sejam naturais, técnicos ou humanos - numa perspectiva orientada para a autossustentação, nos níveis 
local, nacional e regional ${ }^{22}$. Não se trata de rejeitar a cooperação e a solidariedade internacionais, mas de se insistir que elas devem ocorrer nos termos dos países do Terceiro Mundo (SACHS, 1980; 1981 apud STAVENHAGEN, 1985). Uma abordagem orientada para o povo - quer seja de camponeses ou operários, aldeões ou favelados - que deve participar em todos os níveis do processo de desenvolvimento: desde a formulação de necessidades às etapas de planejamento, execução e avaliação, devendo o desenvolvimento ser deslocado dos escritórios dos burocratas para o seu verdadeiro lugar: as bases, o que coloca, naturalmente, o problema do poder político, que é, talvez, a questão fundamental do desenvolvimento hoje.

Nesta apresentação, não se propõe analisar implicações, possibilidades e limitações de uma abordagem alternativa de desenvolvimento, mas mostrar que seu pensamento surge como resultado de uma mudança de ênfase, do questionamento permanente dos paradigmas anteriormente aceitos e não criticados. Abordagem que surge no campo do debate com outras abordagens, e que se propõe a referir questões, termos e conceitos até aqui ignorados pelas demais abordagens. Nas palavras de Stavenhagen (1985, p. 20), "as alternativas de desenvolvimento não são inerentes aos países do Terceiro Mundo ou em desenvolvimento, mas também dos países industrializados, em alguns dos quais tornou-se uma questão política".

Essas ideias gerais sobre desenvolvimento igualmente se aplicam ao caso específico que aqui interessa, o desenvolvimento rural, ou seja, como conceito ancorado no tempo (uma trajetória de longo prazo), no espaço (o território e seus recursos) e nas estruturas sociais presentes em cada caso (KAGEYAMA, 2008).

De acordo com Van der Ploeg et al. (2000 apud KAGEYAMA, 2008), o paradigma da modernização da agricultura, que dominou a teoria, as práticas e as políticas como a principal ferramenta para elevar a renda e levar o desenvolvimento às comunidades rurais, vem sendo substituído, notadamente na Europa, por um novo paradigma, o do desenvolvimento rural, buscando um novo modelo para o setor agrícola, com novos objetivos, como a produção de bens públicos (paisagem), sinergias com os ecossistemas locais, maior valorização das economias de escopo em relação às economias de escala, e a pluriatividade das famílias rurais. O desenvolvimento rural, implicando a criação de novos produtos e novos serviços, associados a novos mercados; procurando formas de redução de custos, a partir de novas trajetórias tecnológicas; tentando reconstruir a agricultura não apenas no nível dos estabelecimentos, mas em termos regionais e da economia rural como um todo; representando, enfim, "uma saída para as limitações e falta de perspectiva intrínsecas ao paradigma da modernização e ao acelerado aumento de escala e industrialização que ele impõe" (PLOEG et al., 2000, p. 395 apud KAGEYAMA, 2008). Segundo os autores, o desenvolvimento rural é um "processo multinível, multiatores e multifacetado".

\footnotetext{
${ }^{22} \mathrm{~A}$ autossustentação significa que o Terceiro Mundo deve contar, basicamente, com suas próprias forças e recursos, mais do que esperar soluções para seus problemas a partir do mundo industrializado.
} 
Quadro 1 - 0 processo de produção agrícola: modernização versus desenvolvimento rural

\begin{tabular}{|l|l|}
\hline \multicolumn{1}{|c|}{ Modelos } & \multicolumn{1}{|c|}{ Principais características da produção agrícola } \\
\hline Modernização & $\begin{array}{l}\text { agricultores como empresários agrícolas } \\
\text { especialização } \\
\text { aumento de escala } \\
\text { intensificação (uso de insumos) } \\
\text { produção orientada pela lógica de mercado (menor } \\
\text { utilização interna da própria produção) } \\
\text { aumento do grau de "commoditização" } \\
\text { dependência crescente de poucos mercados específicos }\end{array}$ \\
\hline Desenvolvimento \\
rural & $\begin{array}{l}\text { esforço para reduzir a dependência do mercado de } \\
\text { insumos externos à unidade produtiva, visando à redução } \\
\text { de custos e ao melhor aproveitamento dos recursos } \\
\text { naturais } \\
\text { introdução de novas atividades que permitam utilizar } \\
\text { mais os recursos internos } \\
\text { produção ambientalmente mais adequada } \\
\text { introdução de práticas de cooperação e pluriatividade } \\
\text { diversificação de produtos e busca de economias de } \\
\text { escopo } \\
\text { maior controle sobre os processos de trabalho }\end{array}$ \\
\hline
\end{tabular}

Fonte: Elaborado a partir de Ploeg et al. (2000 apud KAGEYAMA, p. 61).

Já no caso brasileiro, semelhante a esses dois modelos, tem-se uma versão apresentada por Veiga (2001), mas em termos de projetos alternativos para o campo brasileiro. Veja no Quadro 2.

\section{Quadro 2 - Alternativa estratégica para o desenvolvimento rural brasileiro}

\begin{tabular}{|l|l|}
\hline \multicolumn{1}{|c|}{ Projetos } & Principais características da produção agrícola \\
\hline Agribusiness & $\begin{array}{l}\text { o objetivo é minimizar custos dos gêneros e } \\
\text { matérias-primas que são transferidos para } \\
\text { indústrias de transformação, exportadores, } \\
\text { atacadistas, centrais de compras, etc, que } \\
\text { formam o segundo elo da cadeia produtiva } \\
\text { esse objetivo requer uma corrida tecnológica } \\
\text { que resulta em: } \\
\text { - Especialização das fazendas } \\
\text { - Geração de grande excedente de força } \\
\text { de trabalho não-qualificada }\end{array}$ \\
\hline Desenvolvimento rural & $\begin{array}{l}\text { diversificação das economias locais } \\
\text { diversidade multissetorial } \\
\text { agricultura em sistema de policultura } \\
\text { salubridade do meio ambiente } \\
\text { pluriatividade das famílias rurais para a } \\
\text { absorção da mão de obra }\end{array}$ \\
\hline
\end{tabular}

Fonte: Elaborado a partir de Veiga (2001 apud KAGEYAMA, p. 62). 
Para Murdoch e Marsden (1994), a possibilidade do caminho do desenvolvimento rural está, usualmente, numa mudança do uso da terra. Vários fatores, como as demandas sociais, as políticas de reconversão do uso da terra, o fato de o capital fixar-se na terra, produziram uma série de mercados segmentados de uso da terra orientados a diferentes setores de produção e consumo (atividades agrícola, pecuária, pesca e florestal, recreação, residência, indústrias que se descentralizam, etc.). O peso de cada um desses mercados vai mudando e reconfigurando o desenvolvimento rural, e o espaço rural transforma-se, então, numa "multiplicidade de espaços" no interior de uma mesma área geográfica, cada um com sua lógica, suas instituições e suas redes de atores sociais ${ }^{23}$.

Para Kageyama (2008),

o desenvolvimento rural tem de específico o fato de referir-se a uma base territorial, local ou regional, na qual interagem diversos setores produtivos e de apoio. Ao mesmo tempo, as áreas rurais desempenham diferentes funções no processo geral de desenvolvimento e, ao longo desse processo, essas funções se modificam. A função produtiva, antes restrita à agricultura, passa a abranger diversas atividades, o artesanato e o processamento de produtos naturais e aquelas ligadas ao turismo rural e à conservação ambienta!; a função populacional, que, nos períodos de industrialização acelerada, consistia em fornecer mão de obra para as cidades, agora inverteu-se, sendo necessário o desenvolvimento de infra-estrutura, serviços e oferta de empregos que assegurem a retenção de população na área rural; a função ambiental passa a receber mais atenção após as fases iniciais da industrialização (inclusive do campo), e demanda do meio rural a criação e proteção de bens públicos e quase-públicos, como paisagem, florestas e meio ambiente em geral (KAGEYAMA, 2008, p. 67).

A simples presença de atividades e ocupações diversificadas numa região não constitui, no entanto, garantia de maior dinamismo. Conforme apontam Van der Ploeg et al. (2000 apud KAGEYAMA, 2008), o importante para o desenvolvimento rural são as fontes de sinergias que tais atividades podem representar:

É notável que em muitas experiências de desenvolvimento rural a criação de coesão entre atividades, não apenas no interior da empresa agrícola, mas também entre diferentes empresas agrícolas e entre empresas agrícolas e outras atividades rurais (não-agrícolas), aparece como um elemento crucial, estratégico (VAN der PLOEG et al., 2000, p. 392, apud KAGEYAMA, 2008).

Particularmente importantes são as (potenciais) sinergias entre ecosssis-

\footnotetext{
${ }^{23}$ Exemplo dessa multiplicidade é a tipologia com quatro áreas rurais proposta pelos autores para a Inglaterra: "o 'campo preservado', composto de uma classe média de origem urbana, com atitudes preservacionistas e atividades de lazer e habitação; o 'campo contestado', composto por áreas sem atrativos ambientais e fora dos circuitos de comutação, em que os proprietários tendem a impor seus interesses de desenvolvimento, mas com oposição crescente de recém-chegados, com atitudes mais preservacionistas; o 'campo paternalístico', com predomínio das grandes fazendas tradicionais; e o 'campo clientelístico', situado em áreas remotas e dependentes dos subsídios estatais" (MURDOCH; MARSDEN, 1994 apud KAGEYAMA, 2008, p. 63).
} 
temas locais e regionais, ou entre bens e serviços específicos, cadeias alimentares, movimentos sociais, bem como entre a alocação do trabalho familiar rural para atividades agrícolas ou para atividades não-agrícolas (pluriatividade) ${ }^{24}$.

\section{Reflexões}

A análise do desenvolvimento rural deve contemplar, portanto, o desenvolvimento agrícola e o desenvolvimento da rede urbana local e regional, pois é nesse espaço que muitos membros das famílias agrícolas encontrarão fontes de renda complementares, vitais para a preservação da própria atividade agrícola. Nesse sentido, pode-se considerar que, no Brasil, estados como São Paulo, Minas Gerais e Rio Grande do Sul são áreas privilegiadas para entender os novos rumos do desenvolvimento rural, por contarem com uma agricultura dinâmica e com uma rede urbana densa e difundida, que permite que a integração rural-urbana se manifeste em sua plenitude.

Conforme apresentado por Kageyama (2008), nas análises feitas na Europa e nos Estados Unidos, observa-se que a relação entre a urbanização e o desenvolvimento rural é sempre uma via de mão única, no sentido de que o padrão urbano, mais ou menos disperso, ou mais ou menos concentrado em poucas metrópoles, determina em grande medida as possibilidades que se oferecem aos habitantes rurais para a diversificação de atividades e para o acesso a bens e serviços que antes eram privilégios da cidade.

Nos países desenvolvidos, o capitalismo evoluiu de forma mais integrada em termos setoriais, com avanço e modernização da indústria, bem como a estrutura fundiária e a agricultura, caminhando sem mudanças abruptas e de maneira mais equitativa, o que se refletiu num processo mais ameno de urbanização, que pôde ir absorvendo de maneira menos traumática os excedentes de mão de obra agrícola gerados pela modernização, enquanto que no Brasil, contrariamente, desde a década de 1930 até os anos 1960, houve forte êxodo rural, causado não pela modernização, mas pelo atraso da agricultura, que tornava cada vez mais difícil a sobrevivência das populações rurais, empurrando-as para os grandes centros como São Paulo e Rio de Janeiro, mas também para áreas de acesso ainda possível à terra, como Paraná e Mato Grosso. O êxodo rural se acentua a partir de 1960, agora devido à modernização acelerada da agricultu-

\footnotetext{
${ }^{24}$ A pluriatividade manifesta-se naquelas situações em que a integração da agricultura familiar aos mercados alcança um novo estágio, ou se dá por uma via distinta, que é a do mercado de trabalho. Este processo pode ocorrer tanto naquelas situações em que os agricultores já estiverem inseridos em mercados de produtos, bens e serviços, ou em outras onde a integração produtiva é muito incipiente e a venda da força de trabalho passa a ser a principal mercadoria de troca dos agricultores com o mercado. Isso significa, primeiro, que este processo promove e aprofunda a inserção do agricultor familiar aos circuitos mercantis e, segundo, que essa inserção ocorre segundo as características previamente existentes nos territórios, podendo se dar concomitantemente em mercados de produtos (nas situações que vigora o sistema de integração agroindustrial, por exemplo) e de trabalho, ou apenas através da venda da força de trabalho (SCHNEIDER, 2005, p. 4)
} 
ra, especificamente voltada à agroexportação e à produção de insumos para as grandes agroindústrias (os complexos agroindustriais), agravando os já históricos problemas da urbanização acelerada e desequilibrada. Evidentemente que tal situação influenciou a atual conformação da população da rede urbana nacional, sobretudo a forte caracterização dos problemas decorrentes dessa urbanização (KAGEYAMA, 2008).

Então, pode-se dizer que as condições para o desenvolvimento rural são bem diferentes entre as economias desenvolvidas, especificamente as da Europa e América Latina. Baseado em Sumpsi (2007, apud KAGEYAMA, 2008), alguns pontos de reflexão:

1) Nas décadas de 1960/1970, período de mecanização agrícola, na Europa, havia escassez de mão de obra, o que, consequentemente, permitiu a absorção do excedente de mão de obra rural via atividades urbano-industriais, dadas, também, as baixas taxas de crescimento demográfico. Já no Brasil, em condições comuns às da América Latina como um todo, eram completamente diferentes;

2) enquanto na Europa a modernização agrícola e rural desenvolveu-se em condições de abundância de capitais públicos e privados, para investimentos na infraestrutura social e produtiva no meio rural, sob políticas de apoio e subsídios (por exemplo, a PAC), não só na América Latina e Caribe, mas especificamente no Brasil, embora existisse o apoio de políticas de crédito, na fase inicial da modernização agrícola, as condições para investimentos nas áreas rurais foram (e ainda o são) deficitárias, ou praticamente inexistem na maior parte da região;

3) se, por um lado, as alianças políticas e o consequente pacto social-democrata da política europeia rumo ao desenvolvimento rural focaram políticas de emprego e geração de renda, na América Latina, o recente e crescente consenso social gira em torno da necessidade de redução da pobreza, baseado na prestação de serviços sociais (saúde, educação) e políticas de transferências de renda diretas aos mais pobres;

4) entre a Europa e os países latino-americanos, há uma grande diferença quanto ao peso das áreas rurais marginais. Enquanto na União Europeia em torno de $15 \%$ da população vive em áreas rurais desfavorecidas, na maioria dos países da América Latina as áreas rurais marginais chegam a abrigar cerca de metade da população ${ }^{25}$;

5) quanto ao peso das atividades agrícola e pecuária nas ocupações, em muitos municípios da América Latina, chega-se a atingir em torno de $80 \%$, enquanto que, mesmo nas zonas rurais da União Europeia, esse peso não supera os $40 \%$;

25 Entendendo-se como áreas marginais aqueles espaços distantes, ou fracamente integrados ao mercado, territórios isolados ou periféricos com fraca infraestrutura viária, precário acesso aos meios de comunicação, informação e serviços, bem como populações predominantemente pobres e sem oportunidades 
6) a fragilidade das instituições e políticas públicas para o rural, nas décadas recentes, é um elemento característico dos países latino-americanos, enquanto a maioria dos países da União Europeia dispõe de um sistema político e administrativo descentralizado e maduro (SUMPSI, 2005, p. 7);

7) na União Europeia, o nível de organização dos produtores das áreas rurais é bastante superior, via cooperativas, grêmios, organizações de produtores, sindicatos, organizações profissionais agrárias, entre outras formas de associação, se for comparado com o da América Latina ${ }^{26}$.

Agora, se considerarmos os diferentes contextos históricos até aqui apresentados, identificam-se alguns elementos comuns que podem favorecer o desenvolvimento rural.

A perspectiva relação urbano-rural, via a dinâmica econômica das cidades, principalmente através de atividades terciárias, favorece o desenvolvimento das comunidades rurais adjacentes. Mais, a combinação de uma agricultura familiar consolidada com um processo de urbanização e de industrialização descentralizado, pode gerar um mercado local de consumo de produtos diversificados, assim como o fornecimento de matérias-primas e mão de obra rural para a indústria local (VEIGA, 2000). Considerando Schneider (2005), a pluriatividade das famílias rurais pode permitir a retenção de população e a redução do êxodo rural, assim como a diversidade das fontes de renda possibilitam maior autonomia e, consequentemente, menor dependência da atividade exclusivamente agrícola, possibilitando certa estabilidade no nível de renda.

Assim como programas de geração de emprego e de melhoria da qualidade de vida podem atenuar as migrações e o isolamento, a existência de recursos territoriais que permitam produzir para mercados específicos (por exemplo, vinhos e turismo rural, etc.) possibilitam a internalização de externalidades positivas.

Uma análise do desenvolvimento rural ou de seu potencial deve levar em conta alguns elementos ${ }^{27}$ que podem favorecê-lo, sobretudo quando se adota a abordagem territorial como estratégia de análise. Ao abordar a perspectiva do papel das regiões no processo de desenvolvimento, o território surge como recurso analítico que estabelece um diálogo multidisciplinar, legitimando sistemas de produção territoriais que consideram a geografia (na perspectiva do uso de espaço e poder), a economia espacial (localização das atividades e organização social) e a nova economia institucional (organização social, história e cultural) (SOUZA, 1995). A organização passa a ser tratada como alternativa que os atores escolheram para sua coordenação alternativa ao mercado. Embora toda organiza-

\footnotetext{
${ }^{26}$ Em educação, formação profissional, qualificação dos recursos humanos e capacidade de empreendimento e inovação, a América Latina e Caribe são sensivelmente menores, se considerados em relação à União Europeia, o que se constitui um sério problema para promover o desenvolvimento rural nos países latino-americanos.

27 Organização, instituições, externalidades positivas, práticas participativas, uma sociologia do desenvolvimento focada no ator.
} 
ção pressuponha conflitos ou racionalidades múltiplas ${ }^{28}$, sua instrumentalização pode se dar através de associações (que minimamente resolvessem os conflitos), regras e instituições que o estruturaram; regras de religiões, valores; condutas implícitas, que se passam na memória - embora não se tenha nada escrito, as pessoas continuam produzindo ou tendo certos costumes há tempos - o saber fazer, coordenações de ações, dispositivos cognitivos coletivos. Há também a necessidade de um conjunto de instituições vinculadas entre si, que se dediquem ao fomento da atividade da região considerada ${ }^{29}$ : instituições públicas, como governos locais; instituições educativas, como ensino técnico; e instituições privadas, como associações de produtores, organismos consulares, etc. Esse ambiente de colaboração, difusão de informação técnica ou de mercado, é propiciado pelo fato de os atores comprometidos com essas dinâmicas fazerem parte de uma história comum, principalmente pelos laços culturais e comportamentos comuns. Processos históricos que até poderiam se referir a uma história industrial ou econômica, mas também a uma história política ou religiosa.

\section{Considerações finais}

Refletir sobre o desenvolvimento nos remete às práticas participativas da sociedade civil vis-à-vis a problemática e as políticas de promoção do desenvolvimento. Nos últimos anos, as principais instituições internacionais ${ }^{30}$ de promoção e financiamento do desenvolvimento têm incorporado práticas participativas às suas rotinas operacionais. No Brasil, cada vez mais, é aceita a ideia de que é necessário criar mecanismos que possibilitem a participação mais efetiva e direta da comunidade na formulação, no detalhamento e na implementação das políticas públicas. Enfoque que, em parte, é fruto do processo de democratização do país, e, por outro lado, deve-se a uma nova abordagem que tem predominado no contexto internacional.

A abordagem territorial do desenvolvimento rural tem sua origem relacionada, de um lado, ao reconhecimento de novas dinâmicas espaciais - concepção dos destinos dos espaços rurais e as políticas a ele destinadas; por outro lado, isso acontece num momento histórico marcado por um realinhamento dos instrumentos tradicionais do desenvolvimento.

Entretanto, falar sobre esta abordagem do desenvolvimento rural nos leva

${ }^{28}$ Racionalidade limitada: nós não temos a mesma informação a respeito de tudo.

${ }^{29}$ Desde o final dos anos setenta, economistas neomarshallianos (por exemplo, Becattini, 1979), haviam ressaltado o papel da proximidade geográfica, vinculada a uma proximidade social e organizacional, tratada para compreender as dinâmicas de desenvolvimento industrial que se conheciam em vários países determinados territórios. Existindo nestes distritos um ambiente de competência-colaboração-empréstimo de mão de obra ou capacidade produtiva e prática dentre si de subcontratação. Estes comportamentos procuravam uma maior flexibilização produtiva, alcançando um grau de variedade dos produtos propostos, o que caracterizou a chamada especialização flexível (REQUIERDESJARDINS, 1999).

30 Banco Mundial, Bando Interamericano de Desenvolvimento (BID), United Nations Development Programme (UNDP). 
a considerar o que North (1990) trata, respectivamente, como instituições e a path of institutional change - a dinâmica impulsionada pela existência de incentivos e constrangimentos que reforçam uma determinada direção para as ações dos indivíduos e organismos sociais, uma vez que esta direção tenha sido adotada - uma dependência de caminho que considera a importância da aprendizagem gerada por dinâmicas de longo prazo ${ }^{31}$, onde, segundo North (1990; 1991), as instituições são a regra do jogo na sociedade, ou mais formalmente, são constrangimentos humanamente inventados que moldam a interação humana. Consequentemente, elas estruturam incentivos na troca humana, seja esta política, social ou econômica. A mudança institucional molda os caminhos das sociedades, evoluindo através do tempo, e, a partir daí, a chave e o entendimento da mudança histórica.

Os conceitos orientados ao ator aspiram encontrar espaço para uma multiplicidade de racionalidades, desejos, capacidades e práticas, incluindo os associados com vários modos de instrumentalismo.

A importância relativa destas diversas ideias, sentimentos e maneiras de atuar, para dar forma aos componentes sociais e para provocar a mudança, só pode evoluir num contexto único, e dependerá de uma multiplicidade de componentes interconectados de recursos sociais, culturais e técnicos. Por outro lado, um ponto conceituale chave para a discussão em torno da sociologia do desenvolvimento na perspectiva centrada no ator é a questão da "agência". Muitos autores têm retrocedido para reconsiderar a natureza essencial e importante da "agência humana", cuja noção "metateórica" está no coração de qualquer paradigma revitalizado do ator social e forma o eixo ao redor do qual giram os "planteamientos" que intentam reconciliar as noções de estrutura e ator (LONG, 2007).

Em geral, conforme Giddens (1986, apud Long, 2007), a noção de agência atribui ao ator individual a capacidade de processar a experiência social e desenhar maneiras de lidar com a vida. Dentro de limites de informação e outras restrições (por exemplo, físicas, normativas ou político-econômicas), os atores ${ }^{32}$ sociais possuem "capacidade de saber" e "capacidade de atuar". Intentam resolver problemas, aprendem como intervir no fluxo de eventos sociais ao seu redor, e, em certa medida, estão em torno de suas próprias ações, observando como outros reagem à sua conduta e tomando nota das várias circunstâncias contingentes.

\footnotetext{
${ }^{31}$ Embora cada indivíduo seja um ser único, todos os indivíduos são ligados por alguma coisa em comum - valores, moral, cultura - que tem uma dependência ao longo da história. A chave para concluir a história é o tipo de aprendizado que o indivíduo numa sociedade adquire através do tempo. A transmissão do estoque acumulado de conhecimento ao longo do tempo lembra o termo Path dependence. Conforme North (1994), o termo é usado para descrever a força da influência do passado no presente e no futuro.

${ }^{32} \mathrm{O}$ conceito de ator não deve ser usado para denominar coletividades, aglomerações ou categorias sociais que não têm maneira de discernir para formular ou levar a cabo as decisões (HINDES apud LONG, 2007).
} 
La agencia está encarnada en las relaciones sociales, y solo puede ser efectiva a través de ellas. No sólo es el resultado de poseer ciertos poderes persuasivos o formas de carisma; la habilidad de influir en otros o dejar pasar una orden - por ejemplo, para conseguir que los otros acepten un mensaje particular - descansa sobre todo en "las acciones de una cadena de agentes, cada uno de los cuales 'traduce' [el mensaje] de acuerdo con sus proyectos', y 'el poder se forja aquí y ahora enrolando a muchos actores en un esquema político y social dado' (LATOUR, 1986, p. 264 apud LONG, 2007, p. 50).

Em outras palavras, segundo Long (2007), a agência (e o poder) depende de modo crucial do surgimento de uma rede de atores que devem ser parcialmente, ainda que quase nunca por completo, envolvidos em um "projeto" de alguma outra pessoa ou pessoas. A agência, então, implica a geração e uso ou manipulação de redes de relações sociais e a canalização de elementos específicos (como demandas, ordens, bens, instrumentos e informação) através dos pontos nodais de interpretação e interação. Dessa forma, é essencial tomar conta das maneiras como os atores sociais se comprometem ou são envolvidos em debates acerca da atribuição de significados sociais a eventos particulares, ações e ideias.

No espaço geográfico, a ação de políticas públicas pode ser traduzida pela ação do ator. Deve-se considerar a importância do ator na questão da ação política, pois a política pública não pode ser boa se não houver a participação dos atores locais na sua implementação. Implícita nessa perspectiva está a emergência da sociedade civil, com o desenvolvimento como emergindo das localidades ideia-chave para um processo de desenvolvimento endógeno, cujos grupos locais têm alguma solução, a partir de seus valores e capacidade de inovar, como base para se pensar a heterogeneidade.

\section{Referências}

ABRAMOVAY, Ricardo. Para uma teoria dos estudos territoriais. In: I Colóquio Internacional sobre Desenvolvimento Territorial Sustentável. Florianópolis: UFSC, 2007.

CASTELLS, Manuel. A sociedade em rede. Tradução Roneide Venâncio Majer. 7. ed. São Paulo: Paz e Terra, 2003. (A Era da Informação: economia, sociedade e cultura; v. 1).

KAGEYAMA, Ângela. Desenvolvimento Rural: conceitos e aplicação ao caso brasileiro. Porto Alegre: UFRGS, 2008. (Série Estudos Rurais).

LINCK, Thierry. La economía y la política de la apropiación de los territorios. In: RIELLA, Alberto (Org.). Globalizacion, Desarrollo y Territorios Menos Favorecidos. Montevideo: Rosgal S.A., 2006.

LONG, Norman. Development sociology: actor perspectives. London and New York, Routledge, 2001. Tradução de Horacia Fajardo, Magdalena Villarreal y Pastora Rodrígues. Mexico: El Colegio de San Luis, 2007. 
MACHADO, Jorge Alberto. La Globalização (des)Controlada: crisis globales, desajustes econômicos e impactos locales. São Paulo: Tendenz, 2003.

MAIA, Claudio Machado. Abordagens não dicotômicas do desenvolvimento: ação à distância, tecnologia informacional e o posicionamento estratégico de atores. In: OLIVEIRA, Odete Maria de. Relações Internacionais, Direito e Poder: Atores Estatais na Era da Rede Global. v. III. Ijui: Unijuí, 2016.

MDA. Ministério do Desenvolvimento Agrário. Marco Referencial para Apoio ao Desenvolvimento de Territórios Rurais. Série Documentos Institucionais, 02. Brasília: MDA, 2005.

MOREIRA, Manuel Belo. Globalização econômica: gênese e reflexões prospectivas. In: RIELLA, Alberto (Org.). Globalizacion, Desarrollo y Territorios Menos Favorecidos. Montevideo: Rosgal S.A., 2006.

MURDOCH, J.; MARSDEN, Terry. Reconstituting rurality: class, power and community in the land, development process. London: UCL, 1994.

NORTH, Douglass C. Economic performance through time. American Economic Review, v. 84, n. 3. p. 359-368, 1994.

. Institutions, institutional change and economic development. Cambridge: Cambridge University Press, 1990. Disponível em: <http://books. google.com.br/books?id=oFnWbTqgNPYC\&dq=\%22Institutions, + Institutional+Change,+and+Economic+Performance\%22\&pg=PP1\&ots= sWivRfKmX1\&sig=gjzm6E_uJvTzaPHMB2sBt1z3hAM\&hl=pt-BR\&sa=X\&oi= book_result\&resnum=1\&ct=result\#PPA6,M1>. Acesso em: 29 nov. 2016.

. Institutions. Journal of Economic Perspectives, v. 5, n. 1,

p. 97-112, 1991.

REQUIER-DESJARDINS, Denis. Agro-Industria Rural y Sistemas Agroalimentares Localizados : Cuáles puestas ? In: X Aniversario de PRODAR, Quito, Noviembre de 1999.

RIELLA, Alberto (Org.). Globalizacion, Desarrollo y Territorios Menos Favorecidos. Montevideo: Rosgal S.A., 2006.

RODRIK, Dani. Feasible globalizations. National Bureau of Economic Research (NBER). Working paper series. NBER n. 9129, September 2002.

Symposium on Globalization in Perspective: an Introduction . The Journal of Economic Perspectives, v. 12, n. 4. p. 3-8. Autumn, 1998.

SCHNEIDER, Sergio. O papel da pluriatividade numa estratégia de desenvolvimento rural. In: Seminário Nacional de Desenvolvimento Rural Sustentável. Brasília: MDA, 2005.

SOUZA, Marcelo José Lopes de. O território: sobre espaço e poder, autonomia e desenvolvimento. In: CASTRO, I. E. et al. (Org). Geografia: conceitos e temas. Rio de Janeiro: Bertrand Brasil, 1995.

STAVENHAGEN, Rodolfo. Etnodesenvolvimento: uma dimensão ignorada do pensamento desenvolvimentista. Anuário Antropológico. n. 84, p. 11-44, 1985. 
SUMPSI, José Maria. Experiencias de Desarrollo Territorial Rural en la UE y LAC. In: XLIII Congresso da SOBER - Sociedade Brasileira de Economia, Administração e Sociologia Rural. Ribeirão Preto: SOBER, 2005.

SZTOMPKA, Piotr. Sociologia del Cambio Social. Madrid: Alianza, 1995.

VEIGA, Jose Eli da. A Face Rural do Desenvolvimento. Porto Alegre: UFRGS, 2000. . O Brasil rural precisa de uma estratégia de desenvolvimento. Texto para discussão. São Paulo: FEA, 2001. 